Available online on 22.09.2017 at http://jddtonline.info
Journal of Drug Delivery and Therapeutics
Open Access to Pharmaceutical and Medical Research
$\begin{gathered}\text { (0) 2011-17, publisher and licensee JDDT, This is an Open Access article which permits unrestricted non- } \\ \text { commercial use, provided the original work is properly cited }\end{gathered}$

Open $\odot$ Access

Review Article

\title{
INSIGHT IN TO APPLICATIONS OF THERMAL SINTERING TECHNIQUE IN NDDS SPECIALLY GRDDS
}

\author{
Shaikh Siraj Nawaj*', Saleem Mau Patel ${ }^{1}$, G. J. Khan ${ }^{1}$, K. I. Molvi ${ }^{2}$, Patel M Siddik ${ }^{1}$, Shaoor Ahmad ${ }^{1}$ \\ ${ }^{1}$ Department of Pharmaceutics, Ali-Allana College of Pharmacy Akkalkuwa, Nandurbar, Maharashtra, India \\ ${ }^{2}$ Department of Pharmaceutical Sciences, IBN Sina National College for Medical Studies, Jeddah, Kingdom of Saudi Arabia
}

\begin{abstract}
Oral route the most popular route of administration for systemic action .Oral conventional drug delivery has following limitation of unpredictable gastric emptying rate, short gastro intestinal transit time, and inter subject variability leads in to less bioavailability so goal of drug delivery were not properly achieved by conventional dosage forms. So there is need of sustained drug delivery. The sustained drug delivery can be achieved by matrix tablet wherein a solid drug is dispersed in an insoluble matrix. The matrix tablets can be prepared by wet granulation method or modern thermal sintering technique. Sintering concept in the pharmaceuticals technology is very novel. The term sintering means fusion of particles or formation of welded bonds between particles of polymer. Sintering is a method of heating the material in a sintering furnace below its melting point (solid-state sintering) until its particles adhere to each other. In this process, polymer particles undergo fusion or formation of welded bonds between the each particle. Controlled release oral dosage forms were developed by sintering the polymer matrix to its glass transition temperature. The use of sintering technique adds to the effectiveness of polymers to extend the release of drug from formulation depending upon the duration and temperature of sintering. Sintering technique enhanced the extent of drug retardation from the systems studied is short enough for it to be a suitable candidate for SR formulation. The term sintering means fusion of particles or formation of welded bonds between particles of polymer. The SR oral dosage forms can be developed by sintering the polymer Gastroretentive drug delivery system is facing many challenges which can be overcome by upcoming newly sintered technique. This review article explains about various aspects of sintering technique also highlighted some research work on sintered technology.
\end{abstract}

Keywords: Oral route, sintering, sustain, thermal, drug delivery, research work

Article Info: Received 13 Aug, 2017; Review Completed 14 Sep, 2017; Accepted 14 Sep, 2017; Available online 22 Sep, 2017

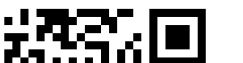

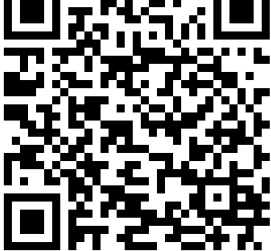

\section{*Address for Correspondence}

Shaikh Siraj Nawaj, Head Department of Pharmaceutics, Ali-Allana College of Pharmacy Akkalkuwa, Nandurbar, Maharashtra, India. E-mail: Sirajsk1234@gmail.com

Cite this article as:

Siraj SN, Patel SM, Khan GJ, Molvi KI, Siddik PM, Ahmad S, Insight in to applications of thermal sintering technique in NDDS specially GRDDS, Journal of Drug Delivery and Therapeutics. 2017; 7(5):109-113

DOI: http://dx.doi.org/10.22270/jddt.v7i5.1510

\section{INTRODUCTION}

Among the delivery routes the most popular route of administration for systemic action is oral route. It is probable that at least $90 \%$ of all the drugs given by oral route. There are different drug deliveries to give drug by oral route Oral route is the most preferred route for the delivery of the drugs till date as it bears various benefits over the other route of drug administration and hence the oral route is the most acceptable from patient compliance aspects, but following problem are associated with oral conventional drug delivery systems like Poor patient compliance, increased chances of missing the dose of a drug with short half-life for which frequent administration is necessary. ${ }^{1}$ Following problems are associated with oral conventional drug delivery system

1. A typical peak-valley plasma concentration- time profile is obtained which makes attainment of steadystate condition difficult.

2. The unavoidable fluctuations of drug concentration may lead to under medication or over medication.

3. The fluctuations in drug levels may lead to precipitation of adverse effects especially of a drug with 
small Therapeutic Index whenever over medication occur. $^{2}$

The sustained drug delivery can be achieved by matrix tablet wherein a solid drug is dispersed in an insoluble matrix. Drug in the outside layer exposed to the bathing solution is dissolved first and then diffuses out of the matrix. The rate of release of drug is dependent on the rate of drug diffusion and not on the rate of solid dissolution. $^{3}$

Gastroretentive drug delivery system approaches witch increase the bioavailability of drug and increase the Gastric retention time in stomach. Gastro retentive drug delivery system plays a vital role among novel drug delivery systems. The retention of oral dosage forms in the upper GIT causes prolonged contact time of drug with the GI mucosa, leading to higher bioavailability, and hence therapeutic efficacy, reduced time intervals for drug administration, potentially reduced dose size and thus patient compliance. ${ }^{4}$

Gastroretentive drug delivery get popularity from last two decades leading to its potential application to improve oral delivery of some important drugs for which prolonged gastro retention can greatly improve their oral bioavailability. GRDDS not only prolong the dosing intervals, but also increase the patient compliance beyond the level of existing controlled release dosage form. The model drug release in control and sustain manners the various approaches are available in the GRDDS like Muchoadhesive, Hydrodynamically based system, swelling and Expanding system, High density system etc. Gastro retentive dosage forms are formulated to be retained in the gastric region for prolonged time and release incorporated drug candidates and thereby enable sustained and prolonged input of the drug to the upper part of the GIT thus leading its optimal bioavailability. Thus, they not only prolong the dosing intervals, but also increase the patient compliance beyond the level of existing controlled release dosage forms. This application is especially effective in delivery of sparingly soluble and insoluble drugs. Gastro retentive dosage forms greatly improved the pharmacotherapy of GIT. ${ }^{5}$

The matrix tablets can be prepared by wet granulation method. Wet granulation method has several advantages over dry granulation method like better flow properties of granules and less generation of dust while mixing. Thermal sintering involves the heating of a compact at a temperature below the melting point of the solid constituents in a controlled environment under atmospheric pressure. It is a simple, effective and economical process to obtain sustained release of drug from the tablet with comparatively less quantity of polymer. The sintering technique is used extensively for sustained release in various drug. ${ }^{6}$

Sintering is defined as the bonding as the bonding of adjacent particle surfaces in a mass of powder or in a compact by the application of heat. Conventional sintering involves the heating of a compact at a temperature below the melting point of the solid constituents in a controlled environment under atmosphere pressure. The sintering process has been used for the fabrication of sustained release matrix tablets and for the stabilization of drug permeability of film coating derived from various pharmaceutical lattices. $^{7}$

Sintering concept in the pharmaceutical sciences is relatively recent. Sintering occurs at elevated temperature and involves mainly three principle steps; joining of the adjacent particles together termed as neck growth, formation of interconnecting pore channels termed as densification followed by formation of spherical shape of particles which tends to flow into the pores within it due to the difference between vapor pressure and cross- sectional area of the pore's neck. These stages of sintering result in bonding of the particles together and ultimately in removal of internal porosity, causing external shrinkage and achievement of desirable physical properties.

Thermal sintering involves heating of a compact at a temperature below the melting points of the solid constituents in a controlled environment. It is simple, effective and economical process. Among the different strategies employed for the design of controlled release dosage forms, sintering technique is one of them. ${ }^{8}$

The sintering method involves the exposure of the dosage form to temperature which softens the polymer matrix and leads to the formation of welded bonds. The drug particle gets entrapped in the matrix formed and these results in the controlled release of the active ingredient. However, this method may be applied only to those drugs that are temperature resistant on exposure which is the limiting factor for many drugs that degrade at elevated temperatures. ${ }^{9}$

\section{Various stages of sintering technique are ${ }^{10,11}$}

I. Inter-particle Bonding: The transport of molecules at the point of particle contact leads to the formation of physical bonding and grain boundaries. The initial bonding takes place rapidly.

II. Neck Growth: Continuing material transport results in the development of a distinct "neck" between particles. The strength of the compact is considerably enhanced at this stage.

III. Pore Rounding: As the neck growth reaches its final stage, the transport of material from the bulk to the neck regions produces a smoothing effect on the pore wall. At this stage, the toughness of the compact is further strengthened

IV. Pore-Channel Closure: The continuing neck growth leads to the closure of some pore channels within the compact, giving rise to isolated pores.

V. Pore Shrinkage: With further sintering, the pores in the compact start to shrink in size and decrease in numbers. This facilitates further densification. This stage involves extensive material transport and the annihilation of vacancies in the compact.

\section{SINTERING METHOD}

Types of sintering methods ${ }^{12,13}$

I. Acetone saturation II Heat treatment 


\section{Acetone Saturation}

The punched tablets were subjected to sintering process. The lower of the desiccators was filled with acetone, closed and kept aside for saturation. After saturation the compressed tablets were taken in petridishes and placed over a wire mesh which was kept above the lower chamber of the desiccator containing acetone. The desiccator was made air tight by closing the lid with the help of wax. The acetone vapors in the saturated dessicator enter the pores of tablets solubilize the surface of the polymer particles which results in fusion of particles, thus bringing about sintering. Tablets of each formulation were divided into 3 batches and exposed to 3 different duration of sintering time $(1.5 \mathrm{hr}, 3.0 \mathrm{hr}, 4.5$ $\mathrm{hr})$. After sintering, the tablet were removed from the desiccator, and dried at room temperature for $24 \mathrm{hr}$ to evaporate the adhering acetone and were finally dried in vacuum desiccator at $300 \mathrm{C}$ over fused calcium chloride to remove the residual acetone from the tablet for $24 \mathrm{hr}$ and stored in desiccator for further studies.

\section{Heat treatment}

Thermal sintering is a method of heating a polymer in a sintering furnace below its melting point (solid state sintering) until its particles adhere to each other. In this process, polymer particles will undergo fusion or formation of welded bonds between each particle. The thermal sintering method involves the exposure of the formulation to a polymer transition temperature in which the polymer forming the matrix slowly softens and welded bonds are formed. The drug particles will be entrapped in the formed matrix, resulting in the controlled release of the active ingredient. However, this method may be applied to only those drugs that are resistant to the temperature of exposure and this may be the limiting factor for many drugs that get degraded at elevated temperatures.

\section{RECENT RESEARCH WORK REPORTED ON SINTERING TECHNIQUE}

1. Satish Polshettiwar et.al 2016 have formulated and evaluated gastro retentive matrix tablets of Carvedilol phosphate by using sintering technique with the help of HPMC K4M, Eudragit, Guar gum polymers as retardant and by using Lactose as filler. Their results revealed that sintering caused decrease in drug release as compared to unsintered tablets. On sintering these formulations for thermal was found that F6, L2, I2 and $\mathrm{H} 4$ gave better results compared to other formulations. ${ }^{14}$

2. Chandan Mohanty et. al 2016 prepared thermally sintered floating matrix tablets of Nicardipine HCL and to study the effect of sintering conditions on in-vitro dissolution study, in-vitro buoyancy properties, hardness and friability. The tablets were prepared by direct compression method using HPMC K100M as matrix forming polymer and sodium bicarbonate as gas generating agent. By using sintering technique floating lag time and total floating time of tablets was found to be decreased and increased respectively, with increase in the sintering temperature and sintering time. In addition the hardness of the sintered tablets was increased with increase in sintering temperature and duration of sintering, where as friability of tablets was found to be decreased with increasing sintering time. ${ }^{15}$

3. Lakshmi P. K et al. 2015 have formulated and evaluated sintered matrix tablets of Lamotrigine using controlled release natural and synthetic polymers such as HPMC K4M, HPMC K15M, HPMC K100M, acacia, guar gum and xanthan gum polymer. Based on the study it can be concluded that sintering technique enhances the extended release of the drug with low concentrations of polymer and it would be a cost effective method. ${ }^{16}$

4. Monica RP Rao et.al 2015 have the present study involved prepared of sustained release matrix tablets of Itopride by using hydrophobic polymers and study of sintering technique in modulating drug release. Carnauba wax and Eudragit L 100 were used as release retarding polymers. A 32optimization design was applied so as to achieve tablets with optimum drug release. Drug release mechanism was found to be diffusion-erosion because of polymer-wax combination. Optimization batches were studied for porosity, contact angle and tensile strength so as to understand effect of sintering on abovementioned properties. Decreased wettability and porosity along with increase in contact angle was evident for sintered tablets. ${ }^{17}$

5. R. R. Bhagwat et.al 2014 have study was to investigate the release characteristics of matrix granules consisting of hydrophobic (i.e waxy) material and Verapamil hydrochloride for sustained release application using thermal sintering technique. The use of sintering technique adds to the effectiveness of polymers to extend the release of drug from formulation depending upon the duration and temperature of sintering. Sintering technique enhanced the extent of drug retardation from the systems studied. ${ }^{18}$

6. Meka Venkata Srikanth et.al 2014 The objective of their investigation was to study the applicability of thermal sintering technique for the development of gastric floating tablets of propranolol $\mathrm{HCl}$. Formulations were prepared using four independent variables, namely (i) polymer quantity, (ii) sodium bicarbonate concentration, (iii) sintering temperature and (iv) sintering time. Floating lag time and $\mathrm{t} 95$ were taken as dependent variables. Tablets were prepared by the direct compression method and were evaluated for physicochemical properties, in vitro buoyancy and dissolution studies. From the drug release studies, it was observed that drug retarding property mainly depends upon the sintering temperature and time of exposure. Optimized formulation was stable at accelerated conditions for a period of six months. PTS so was evaluated for in vivo buoyancy studies in humans for both fed and fasted states and found that gastric residence time of the floating tablets were enhanced by fed stage but not in fasted state. ${ }^{19}$

7. M. Parvathi et.al 2013 have formulated and evaluated sintered matrix tablets of Matrix tablets are preferred to sustain drug activity and reduce frequency of administration. So, the new technique called sintering technique is followed here to obtain sustained release matrix tablets for better patient compliance. Diabetes is a haunting threat for life. so, metformin hcl matrix tablets 
paves the way to increase the quality of life. The term sintering means fusion of particles or formation of welded bonds between particles of polymer. The SR oral dosage forms can be developed by sintering the polymer matrix by exposing to temperature above glass transition point of the polymer or exposing these matrix systems to solvent vapours. ${ }^{20}$

8. Venkata Srikanth Meka et.al 2012 formulated thermally sintered floating tablets of propranolol $\mathrm{HCl}$, and to study the effect of sintering conditions on drug release, as well as their in vitro buoyancy proper- ties. A hydrophilic polymer, polyethylene oxide, was selected as a sintered polymer to retard the drug release. The formulations were prepared by a direct compression method and were evaluated by in vitro dissolution studies. The results showed that sintering temperature and time of exposure greatly influenced the buoyancy, as well as the dissolution properties. As the sintering temperature and time of exposure increased, floating lag time was found to be decreased, total floating time was increased and drug release was retarded. An optimized sintered formulation (sintering temperature $50^{\circ} \mathrm{C}$ and time of exposure $4 \mathrm{~h}$ ) was selected, based on their drug retarding properties. ${ }^{21}$

9.Sameer Shafi et.al 2011 sustained release (SR) sintered matrix tablets of Diltiazem hydrochloride were prepared by trituration method using $4 \%$ and $8 \%$ HPMC K4M and HPMC K15 900ml dissolution medium of $0.1 \mathrm{~N} \mathrm{HCI}$ (pH 1.2) was used for the first 2 hours and $\mathrm{pH} 6.8$ phosphate buffer for remaining 8 hours. The revolutions at $50 \mathrm{rpm}$ and temperature at $37 \pm 1^{\circ} \mathrm{C}$ were maintained. From In vitro drug release profile, formulations $\mathrm{F}$ M and then sintered. The prepared tablets were transferred to the sintering chamber (dessicator filled with acetone in the bottom and equilibrated for 24 hours with vapor) and exposed to different sintering time like 3 hours and 6 hours. The release characteristics study was carried out in USP XXI model. 5, F6 and F9 Keywords: Diltiazem HCL, Sintering, HPMC K exhibited sustained drug release profiles with maximum sustaining effect when compared with unsintered formulation in about 8 hours by using sintering. ${ }^{22}$

10.B. Seshagiri et.al 2011 Hydrodynamically Balanced Systems with sintering technique is an approach to increase the gastric residence time of drugs in stomach. This system is designed for site specific oral drugs with low bulk density than gastric fluids so as to buoyant the dosage form in stomach to increase the residence time of the drug. In the present investigation, an attempt was made to design hydrodynamically balanced drug delivery systems for Glipizide using HPMC K4M and HPMC K15M polymers by solvent casting sintering technique The study reveals that the formulations of HBS of Glipizide formulated has exhibited a floating lag time of less than 5 minutes and floating time of more than $22 \mathrm{hrs}$. The results indicate that gas powered Hydrodynamically Balanced Tablets of Glipizide containing HPMC K15M provides a better option for controlled release action and improved bioavailability. ${ }^{23}$

11. Vaibhav Bhamre et.al 2013 have formulated and evaluated sintered matrix tablets of Stavudine by using Eudragit RS100 \& Compritol 888ATO withdirect compression method. .Also studied effect of different three temperatures on stability of sintered tablets. Storage condiotion \& period of storage affct stability Stavudine sintered tablet. ${ }^{24}$

\section{Future prospective}

Day by day there is need of novel technology in novel drug delivery system.This sintered technology fulfill demand of novel drug delivery system. By exploring the use of sinterted technique in various dosage forms it may factors driving the growth of the pharmaceutical market.

\section{CONCLUSION}

The thermal sintering technique In the pharmaceutical science, sintering has been described as the mechanism for the strengthening of the mechanical properties of consolidated pharmaceutical powders at elevated temperatures, for solid-bond formation during tablet compression, and for thermal curing of polymer-latex film coatings. The concept of sintering was applied in the investigation of the effect of heating on the mechanical properties of pharmaceutical powders. The formation of solid bonds within a powder bed during tablet compression was also studied in terms of sintering. The changes in the hardness and disintegration time of tablets stored at elevated temperatures were described as a result of sintering. The sintering process has been used for the fabrication of sustained release matrix tablets and for the stabilization of the drug permeability of film coatings derived from various pharmaceutical lattice However, a better understanding of the theoretical and technical aspects of the sintering process may allow the identification of its specific needs for pharmaceutical manufacturing such as the fabrication of controlled-release polymeric matrix systems.

There is need to develop new specially designed equipment for utilization of themal sintered technique in novel drug delivery system. 


\section{REFERENCES}

1. Patil H, Tiwari RV, Repka MA. Recent advancements in mucoadhesive floating drug delivery systems: A mini-review. Journal of Drug Delivery Science and Technology. 2016; 31:65-71.

2. Pawar VK, Kansal S, Garg G, Awasthi R, Singodia D, Kulkarni GT. Gastroretentive dosage forms: A review with special emphasis on floating drug delivery systems. Drug delivery. 2011; 18(2):97-10.

3. Shaikh S, Molvi K I. Current trends in gastroretentive floating bioadhesive drug delivery system. International journal of pharmacy and pharmaceutical research. 2016; 6(1):356-67.

4. Garg R, Gupta GD. Progress in controlled gastroretentive delivery systems. Tropical Journal of Pharmaceutical Research. 2008; 7(3):1055-66.

5. Deshpande AA, Rhodes CT, Shah NH, Malick AW Controlled-release drug delivery systems for prolonged gastric residence: An overview. Drug Development and Industrial Pharmacy. 1996; 22(6):531-9. 1

6. Whishead L, Fell JT, Collett JH. Development of gastroretentive dosage form. European Journal of Pharmaceutical Sciences. 1996; 4:S182.

7. Patwekar T S, Rode R B, A Review on Sintering Method in Pharmaceutical Sciences, Asian J. Pharm. Tech, 2014; 4(2): 106-109.

8. Amol R .Bodke, Smita S. Aher, R. B. Saudagar A Review on Sintering Technique in Pharmaceutical Sciences. International Journal of ChemTech Research. 2017; 10(5): 210-215.

9. Rao BS. et al. Studies on release of rifampicin from sintered matrix tablet. Indian Journal of pharmaceutical science. 2001; 63(5):371-378

10. Chandan Mohant sintering technique in pharmaceutical sciences: a brief review. IJPT | 2011; 3(1 ):799-806

11. Rao BS. et al. Design and Evaluation of Eudragit RL 100 sintered matrix tablets. Indian J.Pharm Sci. 2004; 66(2): 202207.

12. Tahseen, G. Sri Vyshnavi, D. Mounika, D. Shina Shankar Prasad A review on matrix drug delivery system. ejpmr, 2017; 4(2), 448-453.

13. Deepika B, Begum S, Faria Patel DM. et al. Design of controlled release non-erodible polymeric matrix tablet using microwave oven-assisted sintering technique. Journal of controlled release, 2002; 84:99-114.
14. Arve SPV, Battuwar A, Hajare R, formulation and evaluation of gastroretentive drug delivery system of carevedilol phosphate by sintering technology. World journal of pharmacy and pharmaceutical science.2016; 5(4):959-978.

15. Mohanty C, Subrahmanyam KV, Mohammad AS, Jena TK, Thermal Sintering Technique: A Novel Strategy Used in the Design of Gastro Retentive Floating Matrix Tablets of Nicardipine $\mathrm{HCl}$ and Its Evaluation. International Journal of Pharma Research and Health Sciences.2016; 4 (1):1004-1009.

16. Lakshmi PK, Husnien Ali M, formulation and evaluation of sintered matrix tablets of lamotrigine. IAJPS 2015; 2(11):1518-1524

17. RP Rao, Shivpuje S, Godbole R, Shirsath C, design and evaluation of sustained release matrix tablets using sintering technique. Int J Pharm Pharm Sci, Vol 8, Issue 2, 115-121.

18. Bhagwat RR, Vaidya II, Formulation of Verapamil Hydrochloride Matrix Granules by Sintering Technique and its Evaluation. Global Journal of Medical research: B Pharma, Drug Discovery, Toxicology and Medicine. 2014; 14(1).

19. Meka VS, Ambedkar SS, Sreenivasa NR, Janaki BR, VenkataRMK. Thermal sintering: a novel technique used in the design, optimization and biopharmaceutical evaluation of propranolol $\mathrm{HCl}$ gastric floating tablets. Drug Dev Ind Pharm, 2014; 40(1): 33-45.

20. Parvathi M. et al. Formulation and evaluation of sintered matrix tablets of metformin hydrochloride and it's comparison over unsintered matrix tablets. International Journal of Research in Pharmacy and Chemistry, 2013; 3(3): 521-530.

21. Meka VS et al; Thermal sintering: a novel technique in the design of gastroretentive floating tablets of propranolol $\mathrm{HCl}$ and its evaluation; Invest Clin; 2012; 53(3): 223-236.

22. Sameer S, Chowdary K.A., Nagoba S, Nangargekar S, "sintered matrix tablets of diltiazem hydrochloride. Int J App Pharm, 2011; 3(3):16-19.

23. Seshagiri B, Chowdary KA, Deepthi Priya Y, "formulation and evaluation of sintered gastro retentive tablets of glizipide", International journal of pharmacy and pharmaceutical sciences, 2011; 3(4).

24. Bhamre V. et al. Stability study of stavudine sintered matrix tablet. International Research Journal of pharmacy. 2013; 4(1):182-186. 